\title{
Analisis Perkembangan Volume Lalu Lintas dan Manfaat Langsung Sebelum dan Sesudah Operasionalisasi Jembatan Suramadu
}

\author{
Achmad Faiz Hadi Prajitno \\ Program Studi Diploma Teknik Sipil FTSP ITS \\ Email: afaizhp@gmail.com
}

\begin{abstract}
Suramadu bridge linking Surabaya to Madura island by road, is expected to become effective and efficient movement and social inequality can be immediately reduced. Transportation flow quickly and effectively will make progress soon skyrocketed Madura, competing with other regions. Tata territory and land use will also be formed in proportion, and also aims to create a reliable road network in anticipation of traffic growth in the future.

In this study discussed about the development of the volume of traffic using the crossing Ferry before the construction of the longest bridge and after the operation the longest bridge in the year 2009 as well as the direct benefits gained. This study as an initial benchmark for accelerating the movement of passenger and goods transport from Surabaya to Madura Island. Review of the development of traffic volumes carried in the past 11 years and 30 years after the operation the longest bridge.

From the calculation, that the volume of passenger traffic and goods occurring before establishing the longest bridge of its development amounted to $-0.659 \%$ for passengers, $6.523 \%$ and $0.930 \% 2$ wheels for 4-wheel vehicles with a minimum amount of 10,095,643 pass per year, 1731. 195 unit veh/yr wheel 2 and 1,514,696 units of veh/yr for wheel 4. Meanwhile, after the operation of the longest bridge in the 2009 th largest amount of traffic volume is, 34,294,786 units of veh/yr for 2 wheel and 9,929,491 units of veh/yr for wheel 4. This means that the construction of the longest bridge is very effective to increase the volume of traffic and the direct benefits in the form of travel time savings are very significant.
\end{abstract}

Keywords: traffic volume, ferry crossing, suramadu bridge.

Abstrak

Jembatan Suramadu, yang menghubungkan Surabaya dengan Pulau Madura melalui jalan darat, diharapkan pergerakan menjadi efektif dan efisien serta ketimpangan sosial dapat segera direduksi. Arus transportasi yang cepat dan efektif akan membuat perkembangan Madura segera melejit, bersaing dengan daerah-daerah lain. Tata wilayah dan tata guna lahan juga akan terbentuk secara proporsional, dan juga bertujuan untuk menciptakan jaringan jalan yang handal dalam mengantisipasi perkembangan lalu lintas pada masa mendatang.

Pada penelitian ini dibahas mengenai perkembangan volume lalu lintas yang menggunakan penyeberangan Ferry sebelum dibangunnya jembatan Suramadu dan setelah dioperasikannya jembatan Suramadu pada tahun 2009 yang lalu serta manfaat langsung yang diperolehnya. Penelitian ini sebagai tolok ukur awal untuk mempercepat pergerakan transportasi penumpang maupun barang dari Surabaya ke Pulau Madura. Tinjauan perkembangan volume lalu lintas dilakukan pada 11 tahun terakhir dan 30 tahun setelah dioperasikannya jembatan Suramadu.

Dari hasil perhitungan diperoleh bahwa volume lalu lintas penumpang dan barang yang terjadi sebelum dibangunnya Jembatan Suramadu perkembangannya adalah sebesar $\mathbf{- 0 , 6 5 9} \%$ untuk penumpang, 6,523 \% roda 2 dan $0,930 \%$ untuk kendaraan roda 4 dengan jumlah minimum sebesar 10.095.643 Png/th, 1.731.195 unit kend/th roda 2 dan 1.514 .696 unit kend/th untuk roda 4. Sedangkan setelah dioperasikannya jembatan Suramadu pada th 2009 jumlah volume lalu lintas terbesar adalah, 34.294.786 unit kend/th untuk roda 2 dan 9.929.491 unit kend/th untuk roda 4. Hal ini berarti bahwa pembangunan jembatan Suramadu sangat efektif untuk meningkatkan volume lalu lintas dan manfaat langsung berupa penghematan waktu perjalanan sangat signifikan.

Kata kunci: volume lalu lintas, penyeberangan ferry, jembatan suramadu. 


\section{Pendahuluan}

Pertumbuhan ekonomi menjadi kunci penting dalam perkembangan sebuah wilayah. Propinsi Jawa Timur dengan jumlah penduduk mencapai 37 juta jiwa, menjadi salah satu propinsi dengan kerapatan penduduk yang padat. Sebagai pintu gerbang Indonesia Timur, Jawa Timur juga memegang kunci penting laju industri dan perdagangan, maka tak dapat ditolak jika jalur transportasi menjadi bagian penting laju roda industri.

Sementara di sisi lain, Pulau Madura yang menjadi bagian dari provinsi Jawa Timur, mengalami kondisi yang kurang menguntungkan. Laju pertumbuhan ekonomi lambat dan income perkapita tertinggal. Jalur transportasi Surabaya Madura yang masih mengandalkan penyeberangan kapal ferry Perak-Kamal. Kondisinya saat ini (2008) sudah sangat padat. Jumlah armada kapal ferry yang digunakan sebanyak 18 buah, yang ratarata usianya juga sudah udzur.

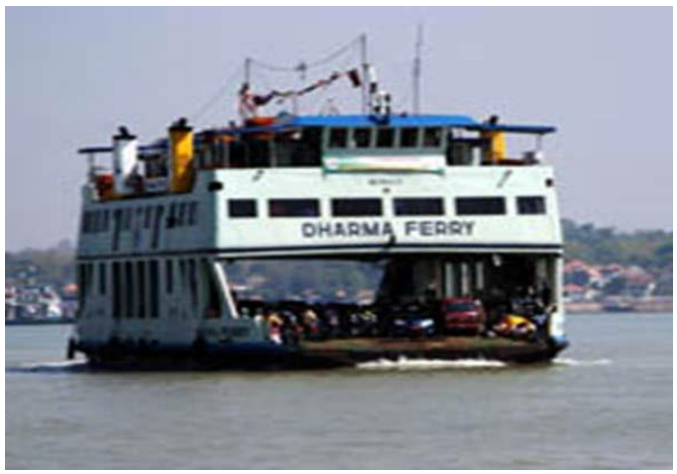

Gambar 1. Kondisi eksisting penyeberangan Ujung - Kamal

Pergerakan jalur transportasi yang terhambat membuat pembangunan jembatan Suramadu dinilai penting sebagai pembuka awal. Dengan Jembatan Suramadu, yang menghubungkan Surabaya dengan Pulau Madura melalui jalan darat, diharapkan ketimpangan sosial dapat segera direduksi. Arus transportasi yang cepat dan efektif akan membuat perkembangan Madura segera melejit, bersaing dengan daerah-daerah lain. Tata wilayah dan tata guna lahan juga akan terbentuk secara proporsional.

Pembangunan jembatan Suramadu tersebut juga bertujuan untuk menciptakan jaringan jalan yang handal dalam mengantisipasi perkembangan lalu lintas pada masa yang akan datang. Karena jembatan ini dijadikan salah satu jalan toll dan dihubungkan dengan jaringan jalan toll lain di Surabaya.

Dengan dijadikannya jembatan Suramadu sebagai jalan toll, penulis mencoba untuk mengevaluasi sejauh mana manfaat langsung yang diperoleh dari pembangunan jembatan tersebut dari sisi penghematan waktu dan biaya perjalanan. Maka disusunlah penelitian ini dengan judul Manfaat Langsung Pembangunan Jembatan Suramadu ditinjau dari Aspek Nilai Waktu dan Biaya Operasi Kendaraan (BOK).

Pada makalah ini akan disajikan analisis perkembangan volume lalu lintas dan manfaat langsung sebelum dan sesudah operasionalisasi jembatan suramadu yang meliputi:

1. Bagaimana perkembangan volume lalu lintas kendaraan yang menyeberang dengan ferry, dan kecepatan penyeberangan ferry dari Tanjung Perak (Ujung) ke Kamal (Bangkalan)?

2. Bagaimana perkembangan volume lalu lintas kendaraan, dan kecepatan kendaraan untuk menyeberang dari 
Surabaya ke Madura setelah ada Jembatan Toll Suramadu?

3. Berapa selisih waktu dan penghematan biaya operasional kendaraan sebelum dan sesudah adanya Jembatan Toll Suramadu?

\section{Nilai Waktu Perjalanan}

Manfaat langsung yang diperoleh dari pembangunan jembatan Suramadu adalah berupa nilai waktu yang pada dasarnya merupakan penghematan waktu perjalanan yang dinilai secara ekonomis untuk masing-masing pemakai jalan (jenis kendaraan). Dan nilai waktu adalah sejumlah uang yang dikeluarkan seseorang untuk menghemat satu unit waktu perjalanan. Nilai waktu biasanya sebanding dengan pendapatan per-kapita, dan merupakan perbandingan yang tetap dengan tingkat pendapatan. Besarnya nilai waktu berbeda-beda menurut jenis kendaraan dan lokasi studi. Dalam penelitian ini nilai waktu dihitung berdasarkan formula dibawah ini (Tamin OZ, 2000):

Nilai Waktu $=$ maksimum $\left\{\left(\begin{array}{lll}k & x & \text { nilai }\end{array}\right.\right.$ waktu dasar), nilai waktu minimum\}

Nilai waktu dapat ditetapkan dari hasil studi nilai waktu yang menggunakan metode produktifitas, stated preference, atau revealed preference.

1. Metode produktivitas adalah metode penetapan nilai waktu yang menggunakan nilai rata-rata penghasilan atau Product Domestic Regional Bruto (PDRB) per-kapita per- tahun yang dikonversi kedalam satuan nilai moneter per-satuan waktu yang lebih kecil (rupiah per-jam)
2. Metode stated preference adalah nilai waktu yang diperoleh melalui wawancara individu untuk kondisi hipotekal tentang berbagai skenario waktu dan biaya perjalanan

3. Metode revealed preference adalah nilai waktu yang diperoleh dari kenyataan pilihan perjalanan yang terjadi dan dikaitkan dengan perjalanan yang ada

\section{Metodologi}

Satu-satunya akses dari Surabaya ke Pulau Madura dan sebaliknya adalah menggunakan penyeberangan kapal ferry Ujung-Kamal. Kondisinya saat ini sudah sangat padat. Jumlah armada kapal ferry yang digunakan sebanyak 18 buah, yang rata-rata usianya juga sudah udzur.

Ferry-ferry tersebut dikelola enam perusahaan, melalui tiga dermaga di masing-masing pelabuhan. Dengan jumlah ferry dan penyeberang yang tak berimbang, menyebabkan waktu tunggu panjang. Dari survei yang dilakukan pada bulan Oktober 2008 didapat volume lalu lintas rata-rata ferry per arah per hari adalah 423 buah kendaraan ringan, 1389 buah truk Kecil, 435 buah truk besar, 349 buah Bus dan 10.892 buah sepeda motor. Kapasitas ferry yang tersedia tersebut sudah jenuh yang diindikasikan dengan waktu tunggu rata-rata kendaraan yang terjadi di pelabuhan Ujung maupun Kamal adalah rata-rata 33.2 menit. Kecuali untuk jenis sepeda motor yang lebih leluasa menembus antrean. Sedangkan waktu yang digunakan untuk menaikkan perjalanan dari pelabuhan ke atas ferry kurang lebih selama 15 menit. Waktu tempuh 
yang diperlukan untuk penyeberangan 30 menit, dan waktu untuk menurunkan perjalanan kurang lebih 15 menit. Jadi total waktu yang dibutuhkan sekitar 60 menit atau satu jam. Waktu ini akan semakin panjang ketika akhir pekan atau musim liburan. Menjelang Lebaran dan Hari Besar Islam malah sering tak terkendali. Budaya "toron" (pulang kampung) bagi masyarakat Madura merupakan menu wajib bagi mereka.

Akibatnya, peningkatan mobilitas manusia dan barang tak dapat terhindarkan. Di lain segi kapasitas ferry tidak bisa ditambah karena dapat mengganggu alur pelayaran yang ada. Keberadaan Jembatan Madura diperkirakan dapat mengurangi waktu tempuh sebesar 60 menit untuk kendaraan yang berasal dan menuju Kec. Kamal, Socah, dan Bangkalan, 110 menit untuk kendaraan yang tidak berasal dan menuju Kec. Kamal, Socah, dan Bangkalan.

\section{Hasil dan Pembahasan \\ 4.1. Volume Lalu-lintas dan Penumpang}

Mengingat jalur ekisting SurabayaMadura adalah penyeberangan ferry, maka data lalu lintasnya berupa data penumpang ferry.

Tabel 1. Data jumlah penumpang ferry Ujung-Kamal tahun 2003-2008

\begin{tabular}{|rcrrrrrr|}
\hline \multirow{2}{*}{ No } & Jenis & \multicolumn{7}{c|}{ Tahun } \\
\cline { 3 - 8 } & Penumpang & \multicolumn{1}{c|}{2003} & \multicolumn{1}{c|}{2004} & \multicolumn{1}{c|}{2005} & \multicolumn{1}{c|}{2006} & \multicolumn{1}{c|}{2007} & \multicolumn{1}{c|}{2008} \\
\hline 1 & Penumpang & $18,799,643$ & $18,602,367$ & $10,724,937$ & $10,329,569$ & $9,991,538$ & $10,883,970$ \\
2 & Golongan I & 2,011 & 2,132 & 2,195 & 2,311 & 2,610 & 3,030 \\
3 & Golongan II & $2,761,927$ & $3,021,464$ & $2,846,401$ & $3,128,315$ & $3,233,832$ & $3,617,245$ \\
4 & Golongan III & 3,209 & 3,246 & 3,325 & 3,304 & 3,429 & 3,583 \\
5 & Golongan IV & 868,091 & 854,535 & 875,887 & 900,032 & 966,358 & 989,085 \\
6 & Golongan V & 696,098 & 717,702 & 727,499 & 732,181 & 735,192 & 750,207 \\
7 & Golongan VI & 3,641 & 3,719 & 3,874 & 3,846 & 3,981 & 4,132 \\
8 & Golongan VII & 0 & 0 & 0 & 0 & 0 & 0 \\
9 & Golongan VIII & 0 & 0 & 0 & 0 & 0 & 0 \\
\hline
\end{tabular}

Sumber: PT. Indonesia Ferry ASDP Kantor Cabang Surabaya

\subsection{Hasil Perhitungan BOK}

Setelah data terkumpul perhitungan dilakukan dengan menggunakan sofware VOC-HDM III, print out input data dan hasil pengolahan data terlampir, dan rekapitulasi hasilnya yang selanjutnya disebut sebagai BOK tahun dasar dalam $\mathrm{Rp} / \mathrm{Km}$.

Setelah BOK dasar diketahui maka dapat di hitung BOK Aktual. Hasil perhitungan BOK aktual dapat dilihat di tabel berikut.

Tabel 2. Hasil Perhitungan BOK aktual

\begin{tabular}{|c|c|c|c|}
\hline $\begin{array}{c}\text { Tipe Kendaraan } \\
\text { BOK Indek }\end{array}$ & $\begin{array}{c}\text { AADT } \\
\text { (kend/hari) }\end{array}$ & $\begin{array}{c}\text { BOK } \\
\text { DASAR }\end{array}$ & $\begin{array}{c}\text { BOK } \\
\text { (Rp/Thn)'10 }\end{array}$ \\
\hline Car/Kend. & & & \\
\hline $\begin{array}{c}\text { Penumpang } \\
1.0406\end{array}$ & 930 & $1,464.74$ & $517,416,919$ \\
\hline $\begin{array}{c}\text { Utility/Kend. } \\
\text { Serbaguna } \\
1.5082\end{array}$ & 814 & $1,030.20$ & $461,497,996$ \\
\hline $\begin{array}{c}\text { Small Bus } \\
\text { (Bus Kecil) } \\
0.9753\end{array}$ & 581 & $1,422.03$ & $294,252,210$ \\
\hline $\begin{array}{c}\text { Large Bus } \\
\text { (Bus Besar) } \\
0.9881\end{array}$ & 156 & $3,687.26$ & $207,448,165$ \\
\hline $\begin{array}{c}\text { Light Truck } \\
\text { (Truk Kecil) } \\
0.9085\end{array}$ & 592 & $1,223.93$ & $240,274,430$ \\
\hline $\begin{array}{c}\text { Heavy Truck } \\
\text { (Truk Besar) } \\
0.9783\end{array}$ & 186 & $3,456.78$ & $229,582,002$ \\
\hline
\end{tabular}

\subsection{Perhitungan Nilai Waktu}

Untuk perhitungan nilai waktu kendaraan bermotor (kecuali kendaraan pribadi/car) dihitung dengan pendekatan UMR. Dari hasil nilai rata-rata UMR diatas maka nilai penghasilan per-bulan adalah Rp. 825.300. Jumlah jam kerja per bulan adalah 176, maka nilai waktu pengendara adalah:

Penghasilan per-bulan/jumlah jam kerja per-bulan = nilai waktu . Rp. 825.300,- / 176 jam $=R p$.

\subsection{9,20/jam}




\section{ISSN.1907-753X}

Untuk perhitungan nilai waktu kendaraan pribadi dibedakan dari perhitungan nilai waktu kendaraan yang lain, karena diasumsikan pengguna kendaraan pribadi memilik nilai pendapatan perbulan yang lebih besar. Untuk nilai pendapatan perbulan pengguna kendaraan pribadi/car diasumsikan Rp. 4.000.000. Jadi perhitungan nilai waktu nya adalah sebagai berikut:

Penghasilan per-bulan/jumlah jam kerja per-bulan = nilai waktu

$R p$. 4.000.000 / $176 \mathrm{jam}=R p$. 22.727,27/jam

\subsection{Perhitungan Benefit (manfaat) Langsung BOK dan Nilai Waktu}

Perhitungan benefit user cost (dari penghematan nilai waktu) atau keuntungan pemakai jalan yaitu membandingkan keuntungan pengguna jalan sebelum dan sesudah adanya proyek jembatan tol Suramadu.

a) Perhitungan user cost sebelum adanya Suramadu:

- Nilai waktu tunggu ferry $( \pm 15$ menit)

- Nilai waktu tunggu perjalanan penyeberangan $( \pm 30$ menit $)$

- Nilai Waktu Bongkar-muat ( \pm 15 menit)

Untuk total perhitungannya dapat dilihat di Tabel 3.

Tabel 3. Nilai Waktu Pengguna Penyeberangan Ferry (dalam jutaan rupiah)

\begin{tabular}{rcccccccc}
\hline & Sepeda & & Utility/ & & Truck & & Truck & Total \\
Tahun & Motor & Car & Pick Up & Minibus & Kecil & Bus & Besar & Pertahun \\
\hline 2010 & $11,500.59$ & $7,992.89$ & $1,492.07$ & $1,171.35$ & $1,171.35$ & 6.52 & 6.52 & $23,341.30$ \\
2011 & $11,953.26$ & $8,203.30$ & $1,531.35$ & $1,185.62$ & $1,185.62$ & 6.66 & 6.66 & $24,072.48$ \\
2012 & $12,405.93$ & $8,413.72$ & $1,570.63$ & $1,199.89$ & $1,199.89$ & 6.8 & 6.8 & $24,803.67$ \\
2013 & $12,858.60$ & $8,624.14$ & $1,609.91$ & $1,214.16$ & $1,214.16$ & 6.94 & 6.94 & $25,534.85$ \\
2014 & $13,311.27$ & $8,834.56$ & $1,649.19$ & $1,228.43$ & $1,228.43$ & 7.08 & 7.08 & $26,266.04$ \\
2015 & $13,763.94$ & $9,044.98$ & $1,688.47$ & $1,242.70$ & $1,242.70$ & 7.22 & 7.22 & $26,997.22$ \\
2016 & $14,216.61$ & $9,255.40$ & $1,727.75$ & $1,256.97$ & $1,256.97$ & 7.36 & 7.36 & $27,728.41$ \\
2017 & $14,669.28$ & $9,465.82$ & $1,767.03$ & $1,271.24$ & $1,271.24$ & 7.5 & 7.5 & $28,459.60$ \\
2018 & $15,121.95$ & $9,676.24$ & $1,806.31$ & $1,285.51$ & $1,285.51$ & 7.64 & 7.64 & $29,190.78$ \\
2019 & $15,574.62$ & $9,886.66$ & $1,845.59$ & $1,299.77$ & $1,299.77$ & 7.78 & 7.78 & $29,921.97$ \\
2020 & $16,027.28$ & $10,097.08$ & $1,884.87$ & $1,314.04$ & $1,314.04$ & 7.92 & 7.92 & $30,653.16$ \\
2021 & $16,479.96$ & $10,307.50$ & $1,924.15$ & $1,328.31$ & $1,328.31$ & 8.06 & 8.06 & $31,384.34$ \\
2022 & $16,932.62$ & $10,517.91$ & $1,963.43$ & $1,342.58$ & $1,342.58$ & 8.2 & 8.2 & $32,115.53$ \\
2023 & $17,385.30$ & $10,728.33$ & $2,002.71$ & $1,356.85$ & $1,356.85$ & 8.34 & 8.34 & $32,846.72$ \\
2024 & $17,837.96$ & $10,938.75$ & $2,041.99$ & $1,371.12$ & $1,371.12$ & 8.48 & 8.48 & $33,577.90$ \\
2025 & $18,290.63$ & $11,149.17$ & $2,081.27$ & $1,385.39$ & $1,385.39$ & 8.62 & 8.62 & $34,309.09$ \\
2026 & $18,743.30$ & $11,359.59$ & $2,120.55$ & $1,399.66$ & $1,399.66$ & 8.76 & 8.76 & $35,040.27$ \\
2027 & $19,195.97$ & $11,570.01$ & $2,159.83$ & $1,413.92$ & $1,413.92$ & 8.9 & 8.9 & $35,771.46$ \\
2028 & $19,648.64$ & $11,780.43$ & $2,199.11$ & $1,428.19$ & $1,428.19$ & 9.04 & 9.04 & $36,502.65$ \\
2029 & $20,101.31$ & $11,990.85$ & $2,238.39$ & $1,442.46$ & $1,442.46$ & 9.18 & 9.18 & $37,233.84$ \\
2030 & $20,553.98$ & $12,201.27$ & $2,277.67$ & $1,456.73$ & $1,456.73$ & 9.32 & 9.32 & $37,965.02$ \\
\hline
\end{tabular}

Sumber: Hasil Perhitungan 
Tabel 4. Nilai Waktu Pengguna Tol Suramadu (dalam jutaan rupiah)

\begin{tabular}{|c|c|c|c|c|c|c|c|c|}
\hline Tahun & $\begin{array}{l}\text { Sepeda } \\
\text { Motor }\end{array}$ & Car & $\begin{array}{c}\text { Utility/ } \\
\text { Pick Up }\end{array}$ & Minibus & $\begin{array}{l}\text { Truck } \\
\text { Kecil }\end{array}$ & Bus & $\begin{array}{l}\text { Truck } \\
\text { Besar }\end{array}$ & $\begin{array}{c}\text { Total } \\
\text { Pertahun }\end{array}$ \\
\hline 2010 & $1,612.96$ & $4,896.39$ & 159.11 & 113.65 & 85.72 & 2.08 & 1.39 & $6,871.31$ \\
\hline 2011 & $1,676.58$ & $5,005.89$ & 162.67 & 116.19 & 86.76 & 2.20 & 1.50 & $7,051.79$ \\
\hline 2012 & $1,740.04$ & $5,116.64$ & 166.27 & 118.77 & 87.80 & 2.31 & 1.62 & $7,233.44$ \\
\hline 2013 & $1,803.50$ & $5,226.14$ & 169.83 & 121.31 & 88.84 & 2.43 & 1.62 & $7,413.66$ \\
\hline 2014 & $1,867.12$ & $5,335.64$ & 173.39 & 123.85 & 89.88 & 2.54 & 1.73 & $7,594.15$ \\
\hline 2015 & $1,930.59$ & $5,446.38$ & 176.99 & 126.42 & 90.92 & 2.66 & 1.85 & $7,775.80$ \\
\hline 2016 & $1,994.05$ & $5,555.88$ & 180.54 & 128.96 & 91.96 & 2.66 & 1.85 & $7,955.91$ \\
\hline 2017 & $2,057.67$ & $5,666.63$ & 184.14 & 131.53 & 93.12 & 2.77 & 1.96 & $8,137.83$ \\
\hline 2018 & $2,121.14$ & $5,776.13$ & 187.70 & 134.07 & 94.16 & 2.89 & 1.96 & $8,318.05$ \\
\hline 2019 & $2,184.60$ & $5,885.63$ & 191.26 & 136.61 & 95.20 & 3.00 & 2.08 & $8,498.38$ \\
\hline 2020 & $2,248.22$ & $5,996.37$ & 194.86 & 139.19 & 96.24 & 3.12 & 2.20 & $8,680.18$ \\
\hline 2021 & $2,311.68$ & $6,105.87$ & 198.42 & 141.73 & 97.28 & 3.23 & 2.20 & $8,860.40$ \\
\hline 2022 & $2,375.15$ & $6,215.37$ & 201.98 & 144.27 & 98.32 & 3.35 & 2.31 & $9,040.74$ \\
\hline 2023 & $2,438.77$ & $6,326.11$ & 205.57 & 146.84 & 99.36 & 3.35 & 2.43 & $9,222.43$ \\
\hline 2024 & $2,502.23$ & $6,435.61$ & 209.13 & 149.38 & 100.40 & 3.47 & 2.43 & $9,402.65$ \\
\hline 2025 & $2,565.85$ & $6,546.36$ & 212.73 & 151.95 & 101.44 & 3.58 & 2.54 & $9,584.45$ \\
\hline 2026 & $2,629.32$ & $6,655.86$ & 216.29 & 154.49 & 102.48 & 3.70 & 2.54 & $9,764.67$ \\
\hline 2027 & $2,692.78$ & $6,765.36$ & 219.85 & 157.03 & 103.63 & 3.81 & 2.66 & $9,945.12$ \\
\hline 2028 & $2,756.40$ & $6,876.10$ & 223.45 & 159.61 & 104.67 & 3.93 & 2.77 & $10,126.92$ \\
\hline 2029 & $2,819.86$ & $6,985.60$ & 227.01 & 162.15 & 105.71 & 4.04 & 2.77 & $10,307.14$ \\
\hline 2030 & $2,883.33$ & $7,095.10$ & 230.56 & 164.69 & 106.75 & 4.04 & 2.89 & $10,487.36$ \\
\hline
\end{tabular}

Sumber: Hasil Perhitungan

b) Perhitungan user cost setelah adanya Suramadu:

- Nilai waktu untuk melalui Suramadu dengan kecepatan rencana $60 \mathrm{~km} / \mathrm{jam}$ untuk kendaraan roda 2 dan $80 \mathrm{~km} / \mathrm{jam}$. Jadi waktu tempuh untuk melalui Suramadu untuk kendaraan roda 2 adalah 5,4 menit, untuk kendaraan roda 4 adalah 4,05 menit

- BOK yang diperlukan untuk melalui Suramadu tiap masingmasing jenis kendaraan

- Biaya tiket tol Suramadu untuk masing-masing kendaraan
Untuk biaya perhitungannya dapat dilihat di Tabel 4 diatas.

Selanjutnya untuk total manfaat biaya perjalanan sebelum dan sesudah pembangunan jembatan suramadu diperoleh sebagai berikut:

- Gol. I : Rp. 2,655,933.40 (dalam juta rupiah)

- Gol. IIa : Rp. 21,548.89 (dalam juta rupiah)

- Gol. IIb : Rp. 18,334.62 (dalam juta rupiah)

\section{Simpulan}

Dari hasil perhitungan penghematan waktu perjalanan dan nilai waktu yang 
akan diperoleh dari operasional jembatan toll Suramadu didapatkan hasil-hasil sebagai berikut:

- Gol. I : Rp. 2,655,933.40 (dalam juta rupiah)

- Gol. IIa : Rp. 21,548.89 (dalam juta rupiah)

- Gol. IIb : Rp. 18,334.62 (dalam juta rupiah).

Dengan demikian, maka manfaat langsung total yang akan diperoleh selama umur operasional jembatan Toll Suramadu 20 tahun adalah sebesar Rp. 2,695,816.91 (dalam juta rupiah).

Dalam perhitungan penelitian ini penulis tidak menghitung manfaat tidak langsung akibat proyek, contohnya adalah pertumbuhan ekonomi, partumbuhan industri, pertumbuhan pariwisata dan kenaikian harga tanah didaerahdaerah yang di hubungkan oleh jalan tol Suramadu. Sebaiknya untuk lebih rinci menghitung studi kelayakan jalan tol Suramadu, dihitung pula manfaat tidak langsung tersebut, untuk mendapatkan hasil yang lebih akurat.

\section{Daftar Pustaka}

Black, J.A. (1981); Urban Transport Planning: Theory and Practice, London; Cromm Helm.

Buletin Ringkas BPS, April 2006; Biro Pusat Statistik

$\begin{array}{cr}\text { Departemen Pekerjaan } & \text { Umum } \\ \text { Direktorat Jendral Bina } & \text { Marga, } \\ \text { "Manual Kapasitas } & \text { Jalan } \\ \text { Indonesia",1997. } & \end{array}$
Departemen Pekerjaan Umum Direktorat Jendral Bina Marga, "Biaya Operasi Kendaraan
(BOK) Untuk Jalan Perkotaan di Indonesia", NO: 026/T/Bt/1995.

Departemen Pekerjaan Umum

Direktorat Jendral Bina Marga.

"Pedoman Konstruksi dan

Bangunan Studi Kelayakan Proyek Jalan dan Jembatan", Pd. T-19-2005-B.

Departemen Perhubungan, No.1/Th V/ April 1998; Warta Penelitian Perhubungan.

Departemen Perhubungan, No.4 /Th VII/ Juli 1995; Badan Penelitian dan Pengembangan Perhubungan.

Departemen Perhubungan, No.04 /THN XIII/ 2006; Warta Penelitian Perhubungan.

Fidel Miro, S.E., M.S.Tr. "Perencanaan

Transportasi untuk Mahasiswa, Perencana, dan Praktisi" ERLANGGA, 2002.

Indikator Ekonomi, Desember 2006 Biro Pusat Statistik

Keadaan Angkatan Kerja Indonesia, Agustus 2006; Biro Pusat Statistik

Morlok, Edward K, (1995); Pengantar Teknik Perencanaan transportasi, Terjemahan oleh: Johan K. Hainim, Penerbit Erlangga, Jakarta.

Murthy, D.N.P and Page, N.W. and Rodin, E.Y; Mathematical Modelling, "A Tool for Problem Solving in Engineering, Physical, Biological and Social Sciences", Pergamon Press, 1990.

Ortuzar, J.de D. and Willumsem, L.G. (1990); Modelling Transport, 
Second Edition, John Wiley and Sons Inc; England.

Ronald E. Walpole, Raymond $\mathrm{H}$.

Myers; Ilmu Peluang dan Statistika untuk Insinyur dan Ilmuan, Penertbit ITB Bandung 1986

Sekolah Tinggi Transport. Vol.III: 02, Januari 2002 ISSN; 1411-2655. Jurnal Manajemen Transportasi.

Stopher, P.R. and Meyburg, A.H.

(1975); Urban Transportation Modelling and Planning, Lexington Books, D.C. Health and Company, Lexington, Massachusetts.

Statistik Indonesia 2006, BPS Jakarta Indonesia

Sukirman, Silvia "Dasar - dasar Perencanaan Geometrik Jalan," NOVA, Bandung, 1999.

Surabaya Dalam Angka 2006, Badan

Perencanaan Pembangunan Kota Surabaya dengan Badan Pusat Statistik Kota Surabaya.

Taaffe, E.J. Gauthier, H.L. and O'Kelly, M.E. (1996); Geografy of Transportation, Second Edition, Prentice Hall, Upper Saddle River, New Jersey.

Tamin, O.Z. (2000); Perencanaan dan Pemodelan Transportasi, Edisi Kedua, Penerbit ITB, Bandung.

World Bank, "The Highway Design and Maintenance Standarts Model Volume 1 The Description of the HDM III Model“", 1987. 